\title{
The role of Staphylococcus aureus surface protein SasG in adherence and biofilm formation
}

Correspondence

Timothy J. Foster

tfoster@tcd.ie
Received 6 February 2007

Revised 27 March 2007

Accepted 13 April 2007

\author{
Rebecca M. Corrigan, ${ }^{1}$ David Rigby, ${ }^{2}$ Pauline Handley ${ }^{2}$ \\ and Timothy J. Foster ${ }^{1}$ \\ ${ }^{1}$ Microbiology Department, Moyne Institute of Preventive Medicine, Trinity College, Dublin 2, Ireland \\ ${ }^{2}$ Faculty of Life Sciences, 1.800 Stopford Building, The University of Manchester, Oxford Road, \\ Manchester M13 9PT, UK
}

Staphylococcus aureus colonizes the moist squamous epithelium of the anterior nares. One of the adhesins likely to be responsible is the $\underline{S}$. aureus surface protein $\underline{G}$ (Sas $G$ ), which has sequence similarity with the proteins Pls (plasmin sensitive) of $S$. aureus and Aap (accumulation associated protein) of Staphylococcus epidermidis. Expression of SasG by a laboratory strain of S. aureus could not be detected by Western immunoblotting. To enable investigation of SasG, the gene was cloned into two expression vectors, the IPTG-inducible pMUTIN4 and the tetracycline-inducible pALC2073, and introduced into S. aureus. Expression of SasG masked the ability of exponentially grown $S$. aureus cells expressing protein A (Spa), clumping factor B (ClfB) and the fibronectin binding proteins $A$ and $B$ (FnBPA and FnBPB) to bind to lgG, cytokeratin 10 and fibronectin, respectively. SasG also masked binding to fibrinogen mediated by both ClfB and the FnBPs. Western immunoblotting showed no reduction in expression of the blocked adhesins following induction of SasG. SasG size variants with eight, six or five B repeats masked binding to the ligands, whereas variants with four, two or one repeats had no effect.

SasG-expressing strains formed peritrichous fibrils $(53.47 \pm 2.51 \mathrm{~nm}$ long) of varying density on the cell wall, which were labelled by immunogold negative staining with anti-SasG antibodies. SasG-expressing strains of $S$. aureus also formed biofilm independently of the polysaccharide intercellular adhesin (PIA). SasG variants with eight, six and five repeats formed biofilm, whereas variants with four, two or one repeats did not. It was concluded that the fibrillar nature of SasG explains its ability to mask binding of $S$. aureus microbial surface components recognizing adhesive matrix molecules (MSCRAMMs) to their ligands and to promote formation of biofilm. In addition, the strong adhesion of SasG to desquamated nasal epithelial cells likely compensates for its blocking of the binding of $S$. aureus ClfB to cytokeratin 10, which is important in adhesion to squames by cells lacking SasG. Several clinical isolates expressed SasG at levels similar to those of SH1000 sasG:: pMUTIN4, indicating that the properties described in the laboratory strain $\mathrm{SH} 1000$ may be relevant in vivo.

\section{INTRODUCTION}

Staphylococcus aureus causes community-acquired and nosocomial infections including infections associated with indwelling medical devices. The natural habitat of $S$. aureus is the moist squamous epithelium in the anterior nares. About $20 \%$ of the human population carry S. aureus permanently in their noses and another $60 \%$ of individuals are intermittent carriers (Kluytmans et al., 1997). Infection rates are higher in carriers than in non-carriers and

Abbreviations: MSCRAMM, microbial surface components recognizing adhesive matrix molecules; PIA, polysaccharide intercellular adhesin; POD, peroxidase. invasive disease is often caused by the patient's own isolate (Peacock et al., 2001).

The ability of $S$. aureus to cause infection is due, in part, to cell surface-associated proteins that mediate attachment to the host extracellular matrix termed MSCRAMMs (microbial surface components recognizing adhesive matrix molecules) (Föster \& Hook, 1998). Clumping factors A and $\mathrm{B}$ (ClfA and $\mathrm{ClfB}$ ), protein $\mathrm{A}$ and the fibronectin binding proteins $\mathrm{A}$ and $\mathrm{B}$ (FnBPA and FnBPB) are characterized by an N-terminal signal sequence for Secdependent secretion and a C-terminal cell wall-anchoring domain (Mazmanian et al., 2001; Navarre \& Schneewind, 1999) for covalent linkage to the cell wall by sortase (Navarre \& Schneewind, 1999). 
A novel surface protein identified by analysis of genome sequences called SasG has sequence similarity to proteins Pls (plasmin sensitive) of S. aureus and Aap (accumulation associated protein) of Staphylococcus epidermidis (Roche et al., 2003a). The $\mathrm{N}$-terminal A region of SasG consists of a unique 157 residue subdomain not present in Pls or Aap and a conserved 224 residue subdomain which is 52 and $59 \%$ identical to that of Pls and Aap, respectively (Fig. 1). SasG of strain 8325-4 has seven 128 residue B repeats and one partial B repeat of 65 amino acids, which are $60-67 \%$ identical to those of Aap and $65 \%$ identical to those of Pls (Fig. 1) (Roche et al., 2003a).

The ability of $S$. aureus to colonize the nasal epithelium is in part due to the MSCRAMMs ClfB (O'Brien et al., 2002) and IsdA (Clarke et al., 2006), which promote adhesion to desquamated epithelial cells. SasG can also promote adhesion to squames, and might contribute to colonization (Roche et al., 2003b). Although strain 8325-4 has a copy of the $s a s G$ gene, expression of Sas $G$ protein is not detected by immunoblotting (Roche et al., 2003b). Paradoxically, weak constitutive expression of SasG from plasmid pKS80 in $S$. aureus 8325-4 partially blocks the ability of MSCRAMMs to interact with ligands in adhesion assays (Roche et al., 2003b), a phenomenon that was originally reported for Pls (Savolainen et al., 2001). Previous studies of SasG are incomplete due to the weak, uncontrollable expression from the vector pKS80 (Roche et al., 2003b). In this paper we achieve high-level controlled expression of SasG, which enables more thorough investigation of the masking effect and the role of SasG in adherence to squamous epithelial cells.

Gram-positive cocci can express fibrillar appendages with adhesive functions that project outwards from the cell wall. Fibrils occur on Streptococcus gordonii ( $\mathrm{McNab}$ et al., 1999), Streptococcus sanguis (Handley et al., 1985), Streptococcus mitis (Elliott et al., 2003) and Streptococcus salivarius (Weerkamp et al., 1986). Fibrils have adhesive functions equivalent to those of fimbriae which have recently been identified on some Gram-positive bacteria (Telford et al., 2006). Very recently, the SasG homologue Aap from Strep. epidermidis has been shown to be present as fibrils on the cell surface (Banner et al., 2007). Thus, we investigated if SasG formed fibrils on the surface of $S$. aureus.
Biofilms are bacterial communities that are resistant to host immune responses and antimicrobial agents (Chuard et al., 1991; Rohde et al., 2005). Biofilm formation occurs in several stages. Initially, cells adhere to a surface, and in $S$. epidermidis this is mediated by the autolysin AtlE (Heilmann et al., 1997). Bacteria then accumulate in multiple layers, leading to the formation of a glycocalyx (Mack, 1999; Mack et al., 2004). The accumulative phase of both $S$. aureus and $S$. epidermidis biofilms is usually supported by the polysaccharide intercellular adhesin (PIA) (Mack, 1999), encoded by the icaADBC locus (Heilmann et al., 1996). However, S. epidermidis strains that lack ica can form biofilms, for example mediated by the Aap protein (Rohde et al., 2005). Biofilm formation also occurs with strains of $S$. aureus that lack ica (Fitzpatrick et al., 2005; Toledo-Arana et al., 2005). It was of interest, therefore, to determine whether SasG could promote biofilm formation.

\section{METHODS}

Bacterial strains, plasmids and culture conditions. Strains and plasmids used in this study are listed in Table 1. Escherichia coli was grown on Luria (L) agar or in L broth. S. aureus was grown in tryptic soy broth (TSB) at $37{ }^{\circ} \mathrm{C}$ with aeration (200 r.p.m.) or statically in brain heart infusion (BHI) broth. Media were supplemented with glucose $\left(0.5 \%\right.$, w/v), ampicillin $\left(100 \mu \mathrm{g} \mathrm{ml}^{-1}\right)$, erythromycin $(10 \mu \mathrm{g}$ $\left.\mathrm{ml}^{-1}\right)$, chloramphenicol $\left(10 \mu \mathrm{g} \mathrm{ml}^{-1}\right)$ or tetracycline $\left(2 \mu \mathrm{g} \mathrm{ml}{ }^{-1}\right)$, where appropriate. SasG expression by sasG::pMUTIN4 and pALC2073sas $G^{+}$in the exponential phase was induced by adding $1 \mathrm{mM}$ IPTG or $60 \mathrm{ng}$ tetracycline $\mathrm{ml}^{-1}$, respectively, with the inoculum (stationary-phase culture diluted 1:100). Expression in stationary phase was induced with $1 \mathrm{mM}$ IPTG or $160 \mathrm{ng}$ tetracycline $\mathrm{ml}^{-1}$, respectively, added to cultures at $\mathrm{OD}_{600} 0.6$ and incubated for $3 \mathrm{~h}$. IPTG $(1 \mathrm{mM})$ or $60 \mathrm{ng}$ tetracycline $\mathrm{ml}^{-1}$ was added to wild-type and pALC2073-containing strains, respectively, as an inducer control.

Molecular techniques. Standard procedures were used (Sambrook \& Russell, 2001). Restriction enzymes and ligase (New England Biolabs or Roche) were used according to the manufacturer's protocol, as was Pfu DNA polymerase (Roche). Oligonucleotides were purchased from Sigma-Genosys.

Plasmid and strain construction. To construct pMUTIN4sas $G^{\prime}$, a $1 \mathrm{~kb}$ fragment of the sas $G$ gene incorporating the ribosome-binding site but not the promoter sequence was amplified by PCR from $S$. aureus strain 8325-4. The forward primer ( $5^{\prime}$-GGGGAATTCGTAAGTAAAGTGGAAAATATGG-3' ${ }^{\prime}$ ) and reverse primer (5'-GCGGGATCCTCCAACCATTTGTGAATTACC- $\left.3^{\prime}\right)$ incorporated a $5^{\prime}$ EcoRI and a

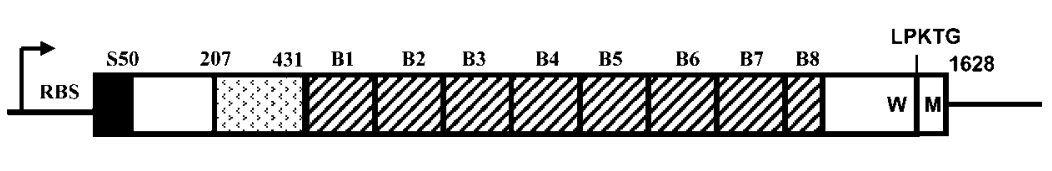

Fig. 1. Schematic organization of SasG of $S$. aureus 8325-4. The $A$ domain lies between the signal sequence $(S)$ and the first $B$ repeat (B1). The positions of the wall/membranespanning regions (W/M) and the LPKTG motif, required for anchoring of the protein to the cell wall by sortase, are indicated. The conserved domain also present in Aap and Pls is indicated by the dotted box. 
Table 1. Bacterial strains and plasmids used in this study

Abbreviations: Em, erythromycin; Tc, tetracycline; Ap, ampicillin; Cm, chloramphenicol.

\begin{tabular}{|c|c|c|}
\hline Strain or plasmid & Relevant characteristics & Reference \\
\hline \multicolumn{3}{|l|}{ Strains } \\
\hline \multicolumn{3}{|l|}{ E. coli } \\
\hline \multicolumn{3}{|l|}{ S. aureus } \\
\hline $8325-4$ & NCTC 8325 cured of prophages & Novick (1967) \\
\hline 8325-4 sasG:: pMUTIN4 & 8325-4 containing pMUTIN4sas $G^{\prime}$ chromosomal insertion $\left(\mathrm{Em}^{\mathrm{r}}\right)$ & This study \\
\hline SH1000 & Strain $8325-4$ with repaired defect in $r s b U$ & Horsburgh et al. (2002) \\
\hline SH1000 sasG::pMUTIN4 & SH1000 containing pMUTIN4sas $G^{\prime}$ chromosomal insert $\left(\mathrm{Em}^{\mathrm{r}}\right)$ & This study \\
\hline SH1000 $\Delta$ ica & SH1000 containing a deletion in the ica gene $\left(\mathrm{Tc}^{\mathrm{r}}\right)$ & Fitzpatrick et al. (2005) \\
\hline $38,148,3151$ & Clinical isolate st 1 & Day et al. (2001) \\
\hline $56,157,3096$ & Clinical isolate st5 & Day et al. (2001) \\
\hline pMUTIN4 & Suicide vector which allows insertion mutagenesis $\left(A p^{r}, E^{r}\right)$ & Vagner et al. (1998) \\
\hline pMUTIN4sas $G^{\prime}$ & pMUTIN4 containing internal $1 \mathrm{~kb}$ sas $G$ fragment $\left(\mathrm{Ap}^{\mathrm{r}}, \mathrm{Em}^{\mathrm{r}}\right)$ & This study \\
\hline pALC2073 & $\begin{array}{l}\text { S. aureus/E. coli shuttle vector containing the tetR gene and } x y l / t e t O \\
\text { promoter }\left(\mathrm{Ap}^{\mathrm{r}}, \mathrm{Cm}^{\mathrm{r}}\right)\end{array}$ & Bateman et al. (2001) \\
\hline pALC2073sas $G^{+}$ & pALC2073 containing full-length $\operatorname{sas} G\left(\mathrm{Ap}^{\mathrm{r}}, \mathrm{Cm}^{\mathrm{r}}\right)$ & This study \\
\hline pALC2073* & pALC2073 with mutated $X m n 1$ sites $\left(\mathrm{Ap}^{\mathrm{r}}, \mathrm{Cm}^{\mathrm{r}}\right)$ & This study \\
\hline pALC2073*sas $G^{+}$ & pALC2073* containing full-length $\operatorname{sas} G\left(\mathrm{Ap}^{\mathrm{r}}, \mathrm{Cm}^{\mathrm{r}}\right)$ & This study \\
\hline pALC2073sasG ${ }^{+} 6 \mathrm{R}, 5 \mathrm{R}$ & pALC2073sas $G^{+}$containing six or five B repeats $\left(\mathrm{Ap}^{\mathrm{r}}, \mathrm{Cm}^{\mathrm{r}}\right)$ & This study \\
\hline $\mathrm{pALC}^{2} 073^{*} \operatorname{sas}^{+} 4 \mathrm{R}, 2 \mathrm{R}, 1 \mathrm{R}$ & pALC2073* ${ }^{\star} a s G^{+}$containing four, two or one B repeats $\left(\mathrm{Ap}^{\mathrm{r}}, \mathrm{Cm}^{\mathrm{r}}\right)$ & This study \\
\hline
\end{tabular}

3' BamHI site, respectively (restriction sites underlined). The PCR fragment was cloned into the EcoRI and BamHI sites of pMUTIN4 and transformed into E. coli. pMUTIN4sas $G^{\prime}$ was introduced into $S$. aureus RN4220 by electroporation, in which it integrated into the chromosomal copy of $s a s G$. It was then transduced into $S$. aureus strains SH1000 and 8325-4 (Foster, 1998).

pALC2073sas $G^{+}$was constructed by amplifying the entire $s a s G$ gene using the forward primer 5 '-CGGGGTACCGTAAGTAAAGTGGAAAATATGG-3' and the reverse primer $5^{\prime}$-GGCGAGCTCGTCTTTCAATCCAACTTTTGG-3', which incorporate a $\overline{5^{\prime} K p n I}$ and a $3^{\prime}$ SacI site, respectively (restriction sites underlined). The PCR product was cloned into pALC2073 between the KpnI and SacI sites. These primers were also used to amplify sas $G$ from clinical isolates in order to estimate the length of the gene and the number of $\mathrm{B}$ repeats.

Mutagenesis of two Xmn1 sites present in the pALC2073 to create pALC2073* was carried out using overlap primer PCR. Complementary primers (5'-GACTCCTGTAAAAAATGACTTCAAAG-3' and 5'-CTTTGAAGTCATTTTTTACAGGAGTC-3'; mutagenic nucleotides underlined) were used to amplify the circular template. The PCR product was treated with $D p n$ I to digest parental DNA and transformed into E. coli XL1-blue. The second Xmn1 site was eliminated using complementary primers (5'-CATTGGAAAACGCTCTTCGGGGCG-3'; mutagenic nucleotide underlined) and (5'-CGCCCCGAAGAGCGTTTTCCAATG-3'; mutagenic nucleotide underlined), using the same procedure.

Variants of $s a s G$ expressing five and six B repeats were isolated during transduction of pALC2073sasG ${ }^{+}$into S. aureus SH1000 and 8325-4. Strains expressing SasG with one, two and four repeats were obtained by partial restriction digestion of the sas $G$ gene in pALC2073* with $X m n 1$. Partial digests were purified, ligated and transformed into XL1-blue.

Coupling of biotin to human fibronectin. Biotin was prepared as previously described (Fitzgerald et al., 2006). Human fibronectin $\left(0.5 \mathrm{mg} \mathrm{ml}^{-1}\right.$ in PBS) was incubated with $2 \mathrm{mg}$ biotin $\mathrm{ml}^{-1}$ for $20 \mathrm{~min}$ at room temperature. The reaction was stopped by addition of $10 \mathrm{mM} \mathrm{NH}{ }_{4} \mathrm{Cl}$. Excess biotin was removed by dialysis against PBS overnight at $4{ }^{\circ} \mathrm{C}$.

Ligand and Western immunoblot analysis. Cell wall-associated proteins of $S$. aureus were prepared as previously described (Roche et al., 2003a). Exponential-phase cultures were grown to $\mathrm{OD}_{600} 0.6$ with the appropriate inducer. Cells were harvested, washed in PBS and resuspended to $\mathrm{OD}_{600} 1$ in lysis buffer $(50 \mathrm{mM}$ Tris/HCl, $20 \mathrm{mM}$ $\mathrm{MgCl}_{2}, \mathrm{pH} 7.5$ ) supplemented with $30 \%(\mathrm{w} / \mathrm{v})$ raffinose and $40 \mu \mathrm{l}$ $\mathrm{ml}^{-1}$ protease inhibitors (Roche). Cell wall proteins were solubilized by incubation with lysostaphin $\left(200 \mu \mathrm{g} \mathrm{ml}^{-1}\right)$ for $10 \mathrm{~min}$ at $37{ }^{\circ} \mathrm{C}$. Protoplasts were recovered by centrifugation and resuspended in lysis buffer with $40 \mu \mathrm{l} \mathrm{ml} \mathrm{m}^{-1}$ protease inhibitors. Supernatant and protoplast fractions were separated on $7.5 \%(\mathrm{w} / \mathrm{v})$ polyacrylamide gels, electrophoretically transferred onto PVDF membranes (Roche), blocked in $10 \%(\mathrm{w} / \mathrm{v})$ skimmed milk (Marvel) and probed with rabbit anti-SasG A domain $(1: 20000$; a gift from Dr M. Meehan, Department of Microbiology, Trinity College, Dublin) or anti-ClfB (1:5000; a gift from Dr E. Walsh, Department of Microbiology, Trinity College, Dublin) antibodies. Bound antibodies were detected using protein A-peroxidase (POD) (1:500; Sigma). Protein A was detected using horseradish peroxidase (HRP)-conjugated chicken 
anti-protein A antibodies (1:5000; Gallus). FnBPs were detected using biotinylated fibronectin and POD-conjugated streptavidin (1:5000; Roche). Proteins were visualized using the LumiGLO reagent and peroxide detection system (Cell Signaling Technology).

Whole-cell immunoblotting. $S$. aureus cells in exponential phase were resuspended to $\mathrm{OD}_{600} 1$ in PBS. Doubling dilutions $(5 \mu \mathrm{l})$ were spotted on a nitrocellulose membrane (Protran). The membrane was blocked and developed as described above.

Adherence assays. Flat-bottomed 96-well microtitre plates (Sarstedt) were coated with doubling dilutions of fibrinogen (Calbiochem) or fibronectin (Calbiochem) in PBS ranging in concentration from 10 to $0.16 \mu \mathrm{g} \mathrm{ml}^{-1}$. Plates were coated overnight at $4{ }^{\circ} \mathrm{C}$ and blocked for $2 \mathrm{~h}$ at $37{ }^{\circ} \mathrm{C}$ with $5 \%(\mathrm{w} / \mathrm{v})$ BSA. S. aureus cells $\left(100 \mu\right.$ l of washed exponential-phase cells, resuspended at $\mathrm{OD}_{600}$ 1 in PBS) were added and incubated for $2 \mathrm{~h}$ at $37^{\circ} \mathrm{C}$. After washing with PBS, adhering cells were fixed with formaldehyde, stained with crystal violet and the $A_{570}$ measured. Binding assays with recombinant cytokeratin 10 (a gift from H. Miajlovic, Department of Microbiology, Trinity College, Dublin) or human IgG (Baxter) were performed with Nunc plates using sodium carbonate buffer instead of PBS.

Transmission electron microscopy. Negative staining was performed by a modification of the method of Handley et al. (1985). Strains were grown to mid-exponential phase and SasG expression was induced with tetracycline at $60 \mathrm{ng} \mathrm{ml}^{-1}$ for $3 \mathrm{~h}$. For negative staining, cells were harvested by centrifugation $(10000 \mathrm{~g}, 2 \mathrm{~min})$, washed three times in distilled water, resuspended in $1: 100$ volume distilled $\mathrm{H}_{2} \mathrm{O}$ and a drop applied to a Formvar-coated copper grid (600 mesh; Agar Scientific) that had been carbon-coated beforehand (Bio-Rad E6200 carbon coater) and plasma-glowed (Plasma Barrel Etcher model PT 7150, Fisons). Bacteria were negatively stained with $2 \%(\mathrm{w} / \mathrm{v})$ methylamine tungstate ( $\mathrm{pH}$ 6.5) (Agar Scientific). Fibril length was measured from the cell wall to the end of the longest fibril at four typical points per cell using Adobe Photoshop CS2 software.

Immunogold negative staining was carried out using a modification of the method of McNab et al. (1999). Bacterial cells and grids were prepared as above. Grids were placed for 5 min onto $25 \mu$ drops of cell suspension. The grids were then inverted onto a $25 \mu \mathrm{l}$ drop of IG buffer [0.05 M Tris, $\mathrm{pH} 8.0$, containing $1 \%(\mathrm{w} / \mathrm{v})$ ovalbumin, $0.1 \%$ $(\mathrm{w} / \mathrm{v})$ gelatin and $0.05 \%(\mathrm{v} / \mathrm{v})$ Tween 20 ] and then onto a $25 \mu \mathrm{l}$ drop of anti-SasG antibody diluted in IG buffer. They were subsequently incubated at ambient temperature for $30 \mathrm{~min}$, washed five times in drops of distilled $\mathrm{H}_{2} \mathrm{O}$, and incubated for $30 \mathrm{~min}$ with $10 \mathrm{~nm}$ diameter gold-anti-rabbit IgG. Grids were washed five times on top of drops of distilled $\mathrm{H}_{2} \mathrm{O}$ and stained with $2 \%(\mathrm{w} / \mathrm{v})$ methylamine tungstate ( $\mathrm{pH}$ 6.5) (Agar Scientific). Control grids were prepared using either pre-immune serum or no primary antibody to test for non-specific binding of the gold particles. Cells were photographed using an FEI Tecnai 12 electron microscope at $100 \mathrm{kV}$.

Bacterial adherence to desquamated epithelial cells. Adherence assays were performed as described previously (O'Brien et al., 2002). Briefly, desquamated nasal epithelial cells were harvested from healthy donors by vigorous swabbing of the epithelium of the nasal septum. After washing in PBS, cells were adjusted to $1 \times 10^{5} \mathrm{ml}^{-1}$. Bacterial cells were washed with $\mathrm{PBS}$ and adjusted to $1 \times 10^{9}$ cells $\mathrm{ml}^{-1}$. Volumes $(100 \mu \mathrm{l})$ of bacterial and epithelial cells were mixed and incubated at $37^{\circ} \mathrm{C}$ for $1 \mathrm{~h}$ with occasional shaking before being captured on $12 \mu \mathrm{m}$ isopore polycarbonate filters, washed with PBS, fixed and stained with $5 \%(\mathrm{w} / \mathrm{v})$ crystal violet. The filters were mounted onto glass slides. The number of bacteria per 100 squames was counted using light microscopy.
Biofilm formation. S. aureus cells were grown overnight in TSB and diluted $1: 200$ in BHI with glucose $(0.5 \%$, w/v). Volumes of $200 \mu \mathrm{l}$ were added to sterile 96-well round-bottomed polystyrene plates (Sarstedt) and incubated at $37^{\circ} \mathrm{C}$ for $24 \mathrm{~h}$. Wells were washed three times with PBS and dried by inversion for $1 \mathrm{~h}$. Adherent cells were stained with $5 \%(\mathrm{w} / \mathrm{v})$ crystal violet and the $A_{570}$ measured. To test the role of proteases, $\alpha_{2}$-macroglobulin (0.5 U, Roche) was added to inoculated wells and the assay continued as described above.

\section{RESULTS}

\section{Expression of SasG by S. aureus}

pMUTIN4 is a suicide vector that allows a gene in the $S$. aureus chromosome to be connected to the IPTG-inducible pSPAC promoter (Vagner et al., 1998). A $5^{\prime}$ fragment of the sas $G$ gene containing the ribosome-binding site and approximately $1000 \mathrm{bp}$ of the coding sequence for the signal sequence and part of the A domain $\left(\operatorname{sas} G^{\prime}\right)$, was amplified by PCR and cloned into the multiple cloning site of pMUTIN4 in E. coli forming pMUTIN4sas $G^{\prime}$. The plasmid was transformed into S. aureus RN4220 selecting for erythromycin resistance. The plasmid underwent a single crossover with the chromosomal $s a s G$ gene, creating a pSPAC-sas $G$ fusion and simultaneously fusing the $5^{\prime}$ sas $G$ truncated gene fragment to lacZ (Vagner et al., 1998). The sasG::pMUTIN4 element was transduced into SH1000 and 8325-4, selecting for erythromycin resistance.

pALC2073 is a multicopy shuttle plasmid that allows expression of genes from the TetR-controlled $x y l /$ tet $O$ promoter (Bateman et al., 2001). The entire sasG gene, including the ribosome-binding site but lacking the promoter, was cloned into the multiple cloning site to generate pALC2073sas $G^{+}$. The plasmid was transformed into S. aureus RN4220 and transduced into SH1000 and 8325-4, selecting for chloramphenicol resistance.

Expression of SasG after induction of SH1000 sasG:: pMUTIN4 by IPTG and SH1000 (pALC2073sas ${ }^{+}$) by tetracycline was measured by whole-cell immunoblotting (Fig. 2). SasG expression directed by pSPAC was only detected in the IPTG-induced sample. No expression was detectable in the uninduced samples, consistent with previous reports that repression in $S$. aureus is tight (Zhang et al., 2000). In contrast, uninduced SH1000 (pALC2073sas $G^{+}$) expressed levels of SasG similar to those of fully induced SH1000 sasG::pMUTIN4, whereas a 16fold higher level of expression occurred when the cells were induced with tetracycline. Addition of IPTG or tetracycline to wild-type SH1000 and SH1000 (pALC2073), respectively, had no effect on expression of SasG, and while IPTG had no effect on growth rate, the addition of tetracycline had a slight inhibitory effect (data not shown). Altogether, a 64-fold higher level of expression of SasG compared to the plasmidfree control was achieved. This is consistent with earlier reports that repression by the TetR repressor over the $x y l /$ tetO promoter is incomplete (Zhang et al., 2000). 


\section{$\mathrm{OD}_{\mathrm{B}} \quad 0.50 .250 .1250 .060 .030 .0150 .0070 .003$}

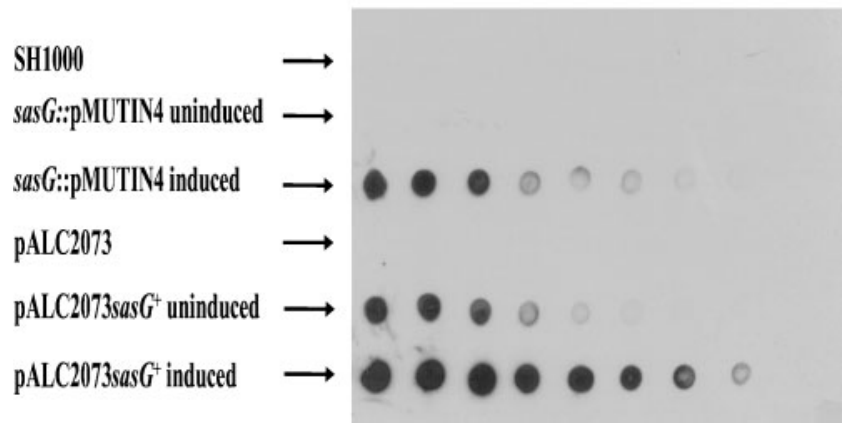

Fig. 2. Whole-cell dot immunoblot of $S$. aureus $\mathrm{SH} 1000$, SH1000 sasG::pMUTIN4 uninduced and induced, SH1000 (pALC2073) empty vector, and SH1000 (pALC2073sasG ${ }^{+}$) uninduced and induced. Serial dilutions of cells were applied to a nitrocellulose membrane and probed with rabbit anti-SasG $A$ domain antibodies and protein A-POD. Similar results were seen for 8325-4 vector-containing strains.

\section{Expression of SasG inhibits adherence of $\mathbf{S}$. aureus to immobilized ligands}

High-level constitutive expression of Pls in S. aureus completely inhibited adherence to fibronectin and fibrinogen, despite normal expression of MSCRAMMs FnBPA and ClfA (Roche et al., 2003b). Partial inhibition of adhesion by SasG was also observed (Roche et al., 2003b). The difference was attributed to the modest level of expression of SasG compared to that of Pls (Roche et al., 2003b). To determine the extent of interference with adhesion by SasG, S. aureus SH1000, SH1000 sasG::pMUTIN4 and SH1000 (pALC2073sasG ${ }^{+}$) were tested for adhesion to immobilized fibrinogen, fibronectin, cytokeratin 10 and IgG (Fig. 3 and data not shown).

Wild-type SH1000, SH1000 sasG::pMUTIN4 uninduced and SH1000 (pALC2073) adhered strongly to cytokeratin 10 (Fig. 3a) and fibrinogen (Fig. 3b) in a dose-dependent and saturable manner. A marked reduction in adherence was observed with IPTG-induced SH1000 sasG: : pMUTIN4 and uninduced SH1000 (pALC2073sasG ${ }^{+}$), whereas induced SH1000 (pALC2073sas $G^{+}$) failed to adhere to either ligand. Similar results were obtained with immobilized IgG and fibronectin (data not shown). This is consistent with the level of SasG expression in Fig. 2, and strongly suggests that high-level expression of SasG can block the adhesins responsible.

\section{Expression of ClfB, the FnBPs and protein A after induction of SasG}

The ability of SH1000 cells from the exponential phase of growth to bind to cytokeratin 10, fibronectin and $\operatorname{IgG}$ is due to $\mathrm{ClfB}, \mathrm{FnBPA}$ and $\mathrm{B}$, and protein A, respectively, each of which is expressed optimally in this phase (McAleese, 2002; Ni Eidhin et al., 1998; Saravia-Otten et al., 1997). In contrast, interactions with fibrinogen are more complex, with ClfB and the FnBPs contributing in the exponential phase. ClfA is the dominant MSCRAMM that binds fibrinogen in cells from the stationary phase (Zhang et al., 2000).

To determine if induction of SasG affected the level of expression of the surface proteins, Western immunoblotting or ligand blotting was performed with proteins that were solubilized by lysostaphin during the formation of stable protoplasts. No significant reduction in the level of ClfA, ClfB, FnBPs or protein A was detected in any of the samples.

To ensure that $\mathrm{ClfB}$, protein $\mathrm{A}$ and the FnBPs were being sorted and covalently attached to the peptidoglycan as normal, the protoplast fractions of the SasG-expressing strains were analysed in the same way, and levels of ClfB, protein A and the FnBPs compared to wild-type and uninduced strains (data not shown). No reactive protein was detected in the protoplast fractions, but intense bands were seen in the solubilized cell wall fraction (Fig. $3 \mathrm{c}$ and data not shown). Thus, sorting of MSCRAMMs appeared to be unimpeded in strains expressing SasG.

\section{SasG forms peritrichous surface fibrils}

Negative staining showed that $S$. aureus SH1000 (pALC2073) and 8325-4 (pALC2073) had few cell-surface fibrils. Cells had a very smooth outer surface (Fig. 4a). A very small number of fibrils were detected on a few cells (data not shown). However, short peritrichous fibrils were expressed on most SH1000 (pALC2073sasG ${ }^{+}$) cells, both with and without induction. The density of the fibrils varied considerably. Most cells had fibrils of intermediate density (Fig. 4b), but about $10 \%$ had very dense fibrils (Fig. 4c). SH1000 (pALC2073sas ${ }^{+}$) expressed more fibrils than 8325-4 (pALC2073sasG ${ }^{+}$). Fibrils of S. aureus SH1000 $\left(\right.$ pALC2073sas ${ }^{+}$) were $53.47 \pm 2.51 \mathrm{~nm}$ in length. The fibrils are extremely thin, and usually individual fibrils cannot be distinguished due to the very close packing, which results in a confluent edge to the fibrillar fringe (Fig. 4c).

To show that fibrils were composed of SasG, SH1000 $\left(\right.$ pALC2073sas $G^{+}$) cells were immunogold-labelled using anti-SasG A domain antibodies. Gold particles labelled the fibrillar fringe (Fig. 4d-f) and covered the whole cell surface. When fibrils were densely packed, the gold was also more densely packed. Both induced (Fig. 4d, e) and uninduced cells (Fig. 4f) of SH1000 (pALC2073sas ${ }^{+}$) showed densely packed fibrillar fringes labelled with the anti-SasG A antibodies. Labelled fibrils covered the surface of dividing cells (Fig. 4f). After division, the newly exposed surface at the septum showed a patch without fibrils (Fig. 4e). This is presumed to be a temporary bare patch, because other non-dividing spherical cells were completely covered in fibrils (data not shown). Individual fibrils were usually very difficult to detect after staining due to masking by the antibodies and gold. 
(a)

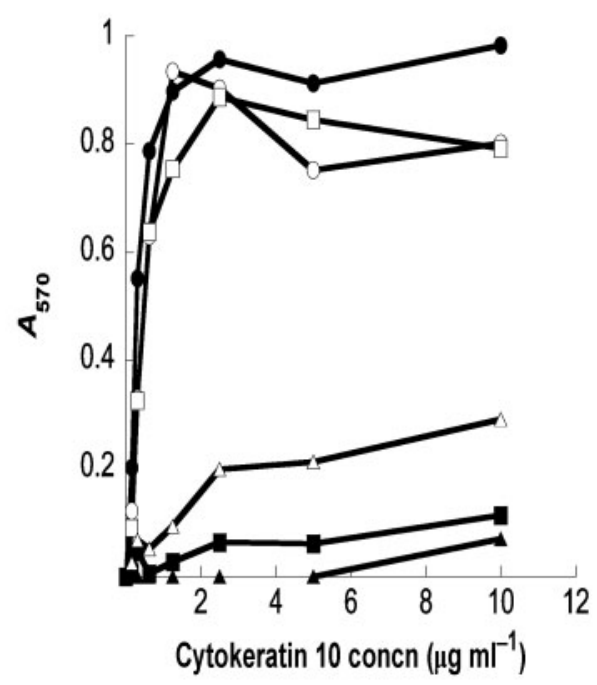

(c)

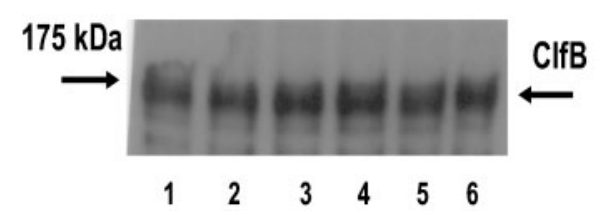

(b)

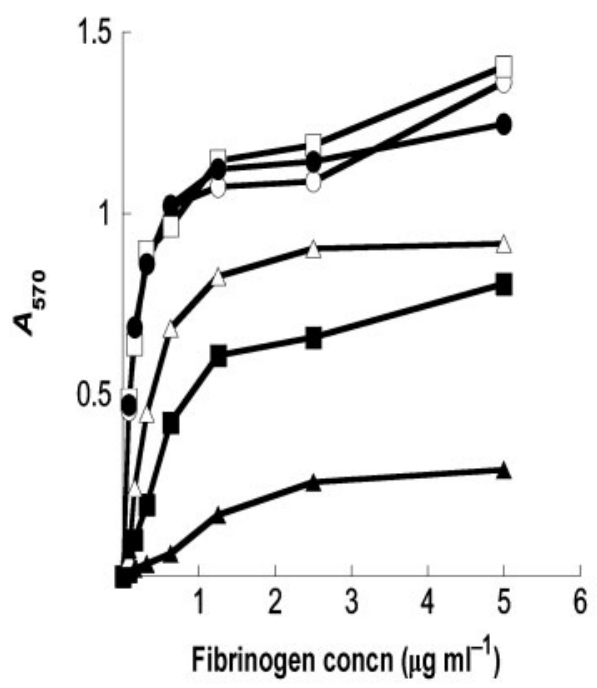

(d)

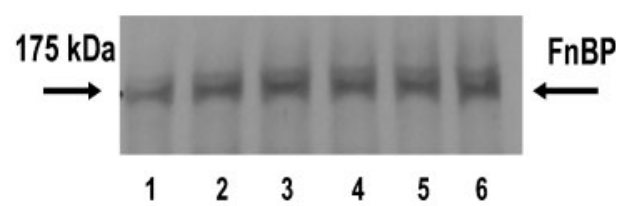

Fig. 3. Adherence of $S$. aureus to cytokeratin 10 and fibrinogen, and analysis of cell wall protein expression. (a, b) Adherence of S. aureus SH1000 with IPTG ( $\bigcirc)$, SH1000 (pALC2073) with tetracycline (•), SH1000 sasG : : pMUTIN4 uninduced ( $\square$ ) and induced $(\boldsymbol{\square})$, and $\mathrm{SH} 1000$ (pALC2073sas $G^{+}$) uninduced $(\triangle)$ and induced $(\boldsymbol{\Delta})$, to immobilized cytokeratin 10 and fibrinogen. All bacteria were grown to exponential phase. Experiments were done in triplicate. Similar results were seen for IgG and fibronectin binding, and using 8325-4 vector-containing strains. (c) Western immunoblot and (d) ligand affinity blotting showing expression of ClfB and the FnBPs in S. aureus SH1000 strains. Lanes: 1, SH1000 wild-type; 2, SH1000 sasG:: pMUTIN4 uninduced; 3, SH1000 sasG:: pMUTIN4 induced; 4, SH1000 (pALC2073); 5, SH1000 (pALC2073sasG ${ }^{+}$) uninduced; 6, $\mathrm{SH} 1000$ (pALC2073sas ${ }^{+}$) induced. Cell wall proteins were released by lysostaphin digestion of $\mathrm{SH} 1000$, run on $7.5 \%$ SDS-PAGE gels and probed with anti-ClfB antibodies or biotinylated fibronectin. The positions of standard molecular mass proteins (in $\mathrm{kDa}$ ) are marked.

The control SH1000 (pALC2073) did not label with the gold-labelled antiserum. Since fibrils are always present when SasG is expressed, and they label with anti-SasG A domain antibodies, it can be concluded that they are composed of SasG.

\section{Mechanism of inhibition of bacterial attachment by SasG}

SasG inhibits adhesion of $S$. aureus to the ligands fibrinogen, fibronectin, cytokeratin 10 and IgG. One explanation for this inhibition is steric hindrance, whereby the B repeats of SasG project the A domain from the cell surface and sterically hinder adhesin-ligand interactions. To investigate this, variants of SasG with reduced numbers of $B$ repeats were isolated either during transduction of
pALC2073sas $G^{+}$or by partial digestion at $\mathrm{XmnI}$ sites within each repeat encoding region. Size variants were identified by cleavage with KpnI and SacI (Fig. 5a), which separates the insert from the vector.

Six out of eight possible sas $G$ size variants were transduced into SH1000. Western immunoblotting demonstrated that the size of the proteins corresponded to the number of $\mathrm{B}$ repeats (Fig. 5b). Adherence assays were performed to measure the ability of shorter SasG variants to prevent adhesion to cytokeratin 10 (Fig. 6a), fibrinogen (Fig. 6b) and fibronectin (data not shown). Strains expressing variants of SasG with eight, six or five repeats masked binding to all three ligands. Variants expressing four, two or one repeats did not block binding. This indicates that the length of SasG is crucial for masking the binding of $S$. aureus to ligands. 

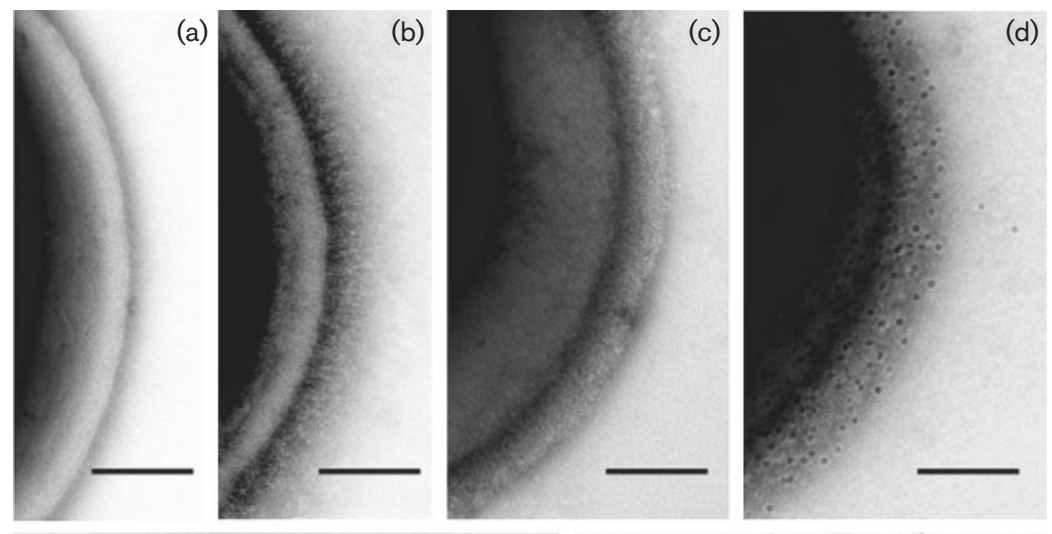

(e)

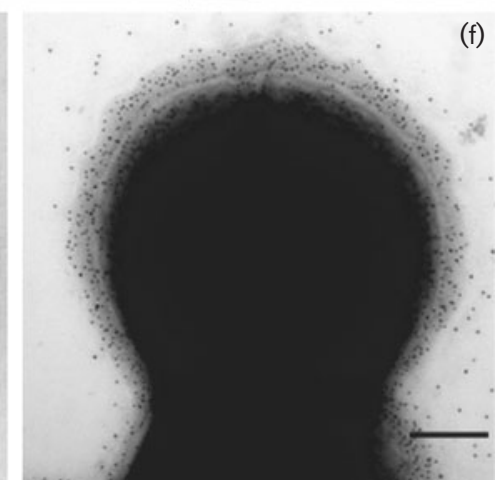

Fig. 4. (a) 8325-4 (pALC2073); (b-f) $\mathrm{SH} 1000$ (pALC2073sasG ${ }^{+}$); (a-c) S. aureus cells negatively stained with $2 \%$ methylamine tungstate; $(d-f) S$. aureus cells negatively stained and immunogold-labelled with antiSasG A domain antibodies and $10 \mathrm{~nm}$ goldconjugated secondary antibody. (a) Early stationary-phase cell showing a typically smooth cell surface. (b) After $3 \mathrm{~h}$ induction, showing peritrichous fibrils $(53.47 \pm 2.51 \mathrm{~nm}$ long) with an intermediate density. (c) After $3 \mathrm{~h}$ induction, $10 \%$ of isolates show a dense layer of closely packed fibrils. Individual fibrils cannot be detected at this fibril density. (d) After $3 \mathrm{~h}$ induction, showing gold particles labelling the SasG A domains at the distal end of the fibrils. This cell has densely packed fibrils and the gold labelling is also dense. (e) After $3 \mathrm{~h}$ induction, showing gold particles labelling the fibrils. This cell, however, displays a bald patch with no fibrils and no gold labelling to one side of the cell. (f) Early stationary-phase cell with no induction, showing gold particles evenly labelling the peritrichous fibrillar fringe of this dividing cell. Fibrils are not visible due to the pale negative staining. Bars, $100 \mathrm{~nm}$.

\section{SasG promotes adherence to desquamated nasal epithelial cells}

Surface proteins $\mathrm{ClfB}$ and IsdA promote adhesion to squames (Clarke et al., 2006; O'Brien et al., 2002). To confirm that SasG can promote adhesion (Roche et al., 2003b), the protein was expressed by inducing SH1000 sasG::pMUTIN4 and pALC2073sas $G^{+}$. Both adhered about three times more strongly to squamous cells than wild-type SH1000 and uninduced SH1000 sasG:: pMUTIN4 (Fig. 7). Uninduced SH1000 (pALC2073sas $G^{+}$) adhered to squames at the same level as induced SH1000 $\left(\right.$ pALC2073sas $\left.G^{+}\right)$. These experiments were performed using bacteria from the exponential phase of growth, at which ClfB is optimally expressed but its adhesive properties would be masked by SasG (Fig. 3). However, adhesion to squames promoted by SasG ( 5500 adherent bacteria per 100 squames) more than compensated for that determined by ClfB ( 1800 bacteria per 100 squames) seen in the controls in which SasG was not expressed.

\section{Expression of SasG in S. aureus causes biofilm formation}

The SasG homologue Aap induces biofilm formation independently of ica (Rohde et al., 2005). Here, the possible role of SasG in S. aureus biofilms was investigated. SH1000 expressing SasG from either sasG::pMUTIN4 or pALC2073sas $^{+}$grew as biofilms, whereas wild-type
SH1000 and SH1000 (pALC2073) did not (Fig. 8a). Uninduced cultures of SH1000 (pALC2073sas ${ }^{+}$) expressed sufficient levels of protein for biofilm formation. Biofilm formation by SasG occurred independently of ica (Fig. 8a).

\section{Biofilm formation by SasG is dependent on the level of protein induction}

To investigate whether biofilm formation was dependent on the level of SasG, IPTG at concentrations ranging from 0 to $0.7 \mathrm{mM}$ was added to SH1000 sasG::pMUTIN4 cultures and biofilm formation was measured (Fig. 8b). IPTG did not stimulate biofilm formation by SH1000 wildtype. This showed that biofilm formation is dependent on the level of SasG expression.

\section{Formation of a biofilm is dependent on the length of SasG}

SH1000 variants carrying pALC2073 expressing SasG with eight, six and five B repeats resulted in the formation of a biofilm. Strains expressing four, two or one B repeats did not form biofilms (Fig. 8c). This showed that in SasG, five $\mathrm{B}$ repeats is the minimum number required for a biofilm to form. The level of SasG expression by B-repeat variants was shown to be the same by whole-cell immunoblotting with anti-A domain antibodies (data not shown). 
(a)

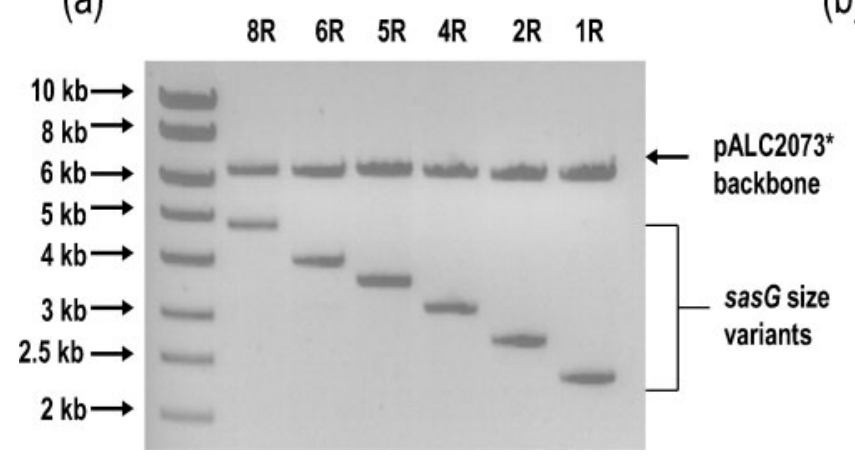

(b) 8R $\quad 6 R \quad 5 R \quad 4 R \quad 2 R \quad 1 R$

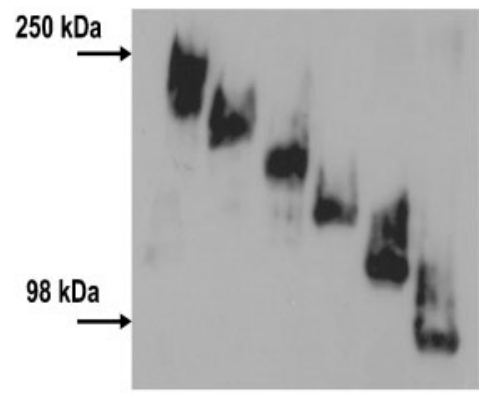

Fig. 5. (a) Gel of a restriction digest showing six different pALC2073sas ${ }^{+}$or $p A L C 2073^{*}$ sas $^{+}$size variants. The different sizes of sas $G$ can be visualized by cutting the entire gene out of pALC2073sasG ${ }^{+} / p A L C 2073^{*}$ sasG $^{+}$with $\mathrm{Kpnl}_{\text {and }}$ Sacl. The different numbers of $B$ repeats $(R)$ present in each gene are indicated. The positions of the molecular mass markers are indicated (in kb). (b) Western immunoblot of the six different pALC2073sasG ${ }^{+} / \mathrm{pALC2073}{ }^{*}$ sasG $^{+}$size variants. The different numbers of $B$ repeats $(R)$ present in each gene are indicated. The positions of standard molecular mass proteins (in $\mathrm{kDa}$ ) are marked.

\section{Proteolysis of SasG is essential for biofilm formation}

To determine whether, as for Aap, proteolytic processing of SasG is required for biofilm formation, the protease inhibitor $\alpha_{2}$-macroglobulin was added to culture-containing wells and biofilm formation was measured (Fig. 8d). This experiment showed that $\alpha_{2}$-macroglobulin has the ability to block biofilm formation in SasG-expressing strains. This ability was lost by inactivating the protease inhibitor by heating at $65{ }^{\circ} \mathrm{C}$ for $20 \mathrm{~min}$. It can be concluded from this that SasG must undergo proteolytic processing for a biofilm to form.

\section{SasG expression by clinical isolates of $\mathbf{S}$. aureus}

Comparative genomic DNA microarray analysis of $S$. aureus isolates from community-acquired invasive disease or carriage by healthy donors has identified ten dominant clonal complexes (CCs) based on multilocus sequence typing (MLST) (Lindsay et al., 2006). The sas $G$ gene is present in strains from $50 \%$ of the CCs (CC1, CC5, CC8, CC15 and CC22; Lindsay et al., 2006). Fifteen clinical isolates representing strains from these CCs were examined by Southern blotting using a probe designed to recognize the A region of sasG. Of the 15 strains tested, all but one, strain 3151, contained the gene (data not shown).

Western immunoblotting was used to determine whether the $s a s G^{+}$clinical strains expressed SasG protein. Eight of the 14 strains expressed SasG, some at levels higher than that of the control 8325-4 sasG::pMUTIN4 induced with $0.4 \mathrm{mM}$ IPTG (Fig. 9). As the level of SasG expressed from the control is sufficient to form biofilm (Fig. 8b), it is likely that these clinical isolates can do likewise. The proteins ran at different sizes due to variation in the number of $\mathrm{B}$ repeats (Fig. 9). PCR was used to amplify the genes from the eight clinical isolates, and the number of $\mathrm{B}$ repeats was determined by comparison with the pALC2073 ${ }^{*}$ sas $G^{+}$size variants (data not shown). Strains 40 and 125 contained seven B repeats, strains 207, 3093 and 3178 contained six repeats, and strain 410 contained 10 repeats, implying that these proteins are of sufficient length to contribute to masking, biofilm formation and nasal colonization. Strains 56 and 148 contained three and two B repeats, respectively (data not shown).

\section{DISCUSSION}

S. aureus colonizes the moist squamous epithelium of the anterior nares. The ability to adhere to squamous cells is believed to be instrumental in colonization. Surface proteins $\mathrm{ClfB}$ and IsdA have been shown to promote adhesion to squames (Clarke et al., 2006; O'Brien et al., 2002) and to be required for colonization of the nares of rodents (Clarke et al., 2006; Schaffer et al., 2006). When expressed in Lactococcus lactis and S. aureus from the weak constitutive promoter in $\mathrm{pKS} 80$, it is evident that SasG can also promote adhesion to squames (Roche et al., 2003b), and this was confirmed here by the strong adhesion seen when SasG was expressed at high levels. The chromosomal $s a s G$ gene is not expressed at a detectable level by laboratory strains; however, expression has been noted in clinical isolates. Paradoxically, when SasG was expressed at high levels it masked binding of MSCRAMMs to their ligands, including ClfB, which binds cytokeratin 10 and which is important in promoting adhesion to squames (O'Brien et al., 2002). However, the ability to adhere to squames is preserved by the adhesive properties of SasG (Roche et al., 2003b).

The masking effect by SasG can be explained by the fact that it has a fibrillar structure, and individual molecules are 


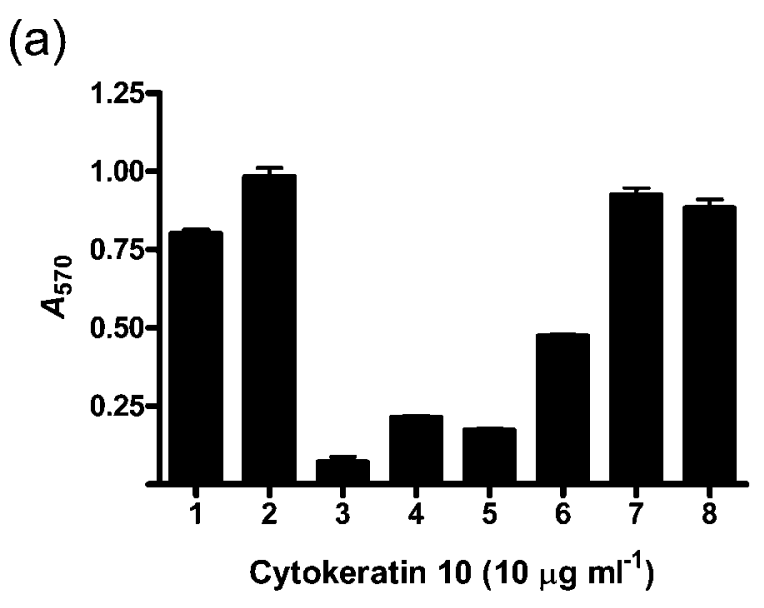

(b)

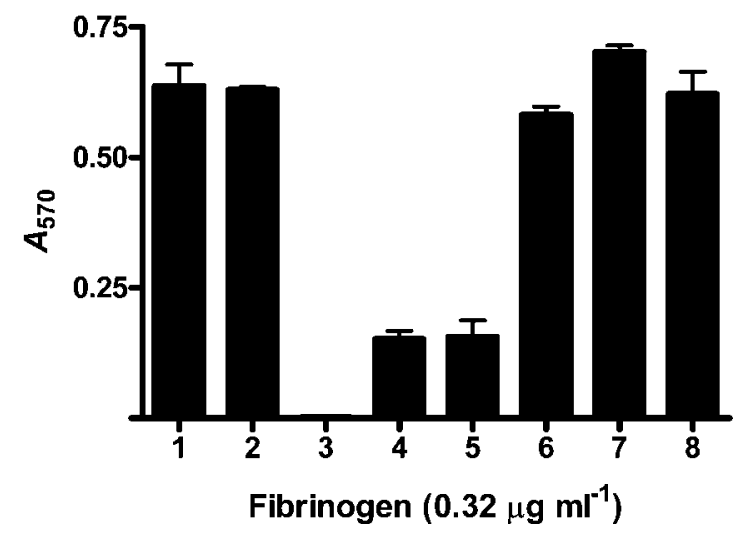

Fig. 6. Adherence assay showing the masking effect of SasG. $(a, b)$ Binding of 1, SH1000; 2, SH1000 (pALC2073); 3, SH1000 $\left(\mathrm{pALC} 2073\right.$ sasG $\left.{ }^{+}\right) ; 4, \mathrm{SH} 1000$ (pALC2073sasG ${ }^{+}$6R); 5, SH1000 (pALC2073sas ${ }^{+}$5R); 6, SH1000 (pALC2073*sas ${ }^{+}$4R); 7, SH1000 (pALC2073*sasG ${ }^{+}$2R) and 8, SH1000 (pALC$2073^{*}$ sas $^{+}{ }^{+} \mathrm{R}$ ) to cytokeratin 10 and fibrinogen, respectively. All strains containing pALC2073 or pALC2073sas $G^{+}$size variants were grown in the presence of $60 \mathrm{ng}$ tetracycline $\mathrm{ml}^{-1}$. Adherence was measured using crystal violet staining and read at $A_{570}$. Experiments were done in triplicate; error bars show SDs.

packed quite densely on the cell surface as peritrichous fibrils with a mean length of $53.47 \pm 2.51 \mathrm{~nm}$. A similar molecule, Aap, also has a fibrillar morphology, but is longer $(122 \pm 10.8 \mathrm{~nm})$ and is localized on the cell surface in fibrillar tufts (Banner et al., 2007). Although these two LPXTG-anchored proteins have significant sequence similarity (Roche et al., 2003a) they are organized very differently on the cell surface. The fact that SasG fibrils completely cover the cell surface probably explains why SasG is able to physically mask the functioning of the smaller adhesins closer into the surface, as shown in this paper. It has previously been suggested that the $B$ repeats act as a stalk to project the ligand-binding A region of the protein away from the cell surface (Roche et al., 2003b).

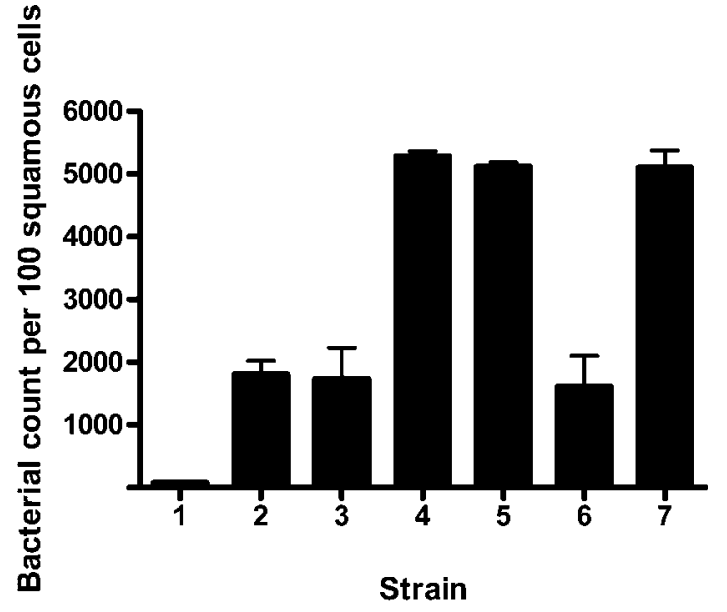

Fig. 7. Bacterial adherence to desquamated nasal epithelial cells. 1, PBS alone; 2, SH1000 with IPTG; 3, SH1000 (pALC2073) with tetracycline; 4, SH1000 (pALC2073sasG ${ }^{+}$); 5, SH1000

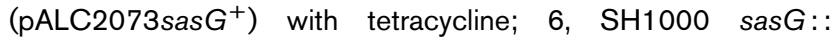
pMUTIN4; and 7, SH1000 sasG::pMUTIN4 with IPTG. These were tested for their ability to bind to human desquamated epithelial cells. Counts represent the number of bacterial cells adhering to 100 squamous cells. Results are expressed as the mean \pm SD of triplicate experiments.

This prediction is confirmed by this study, as the antiserum directed against the A domain appeared to bind to the ends of the fibrils.

The property of masking the adherence of $S$. aureus to the immobilized ligands fibronectin, fibrinogen, cytokeratin 10 and IgG was shown to be dependent on the level of expression of SasG and the number of $B$ repeats, which presumably determines the length of the fibrillar molecule. When the repeats were fewer than five in number, the masking phenotype was lost. Analysis of the sequenced strains of $S$. aureus shows that the number of B repeats can vary from three to eight in different strains, with the sas $G$ gene of Mu50 and N315 containing three B repeats, Col containing five, MSSA476 containing six and 8325-4 containing eight (Roche et al., 2003a). When the size of the SasG protein from clinical isolates was examined, the number of $B$ repeats was seen to vary from two to ten. This would imply that SasG has a functional role in masking or biofilm formation in six out of the eight SasG-expressing clinical strains. Expression of proteins containing two and three repeats was noted. SasG would most likely not have a functional role in masking and biofilm formation in these strains. However, it is possible that a protein of this size may have another as yet unknown function.

It might seem contradictory that an $S$. aureus surface protein would prevent adhesion to extracellular matrix components. However, it is possible that at certain stages during infection it is advantageous for bacteria to detach from a ligand to which they are attached, thus allowing 
(a)

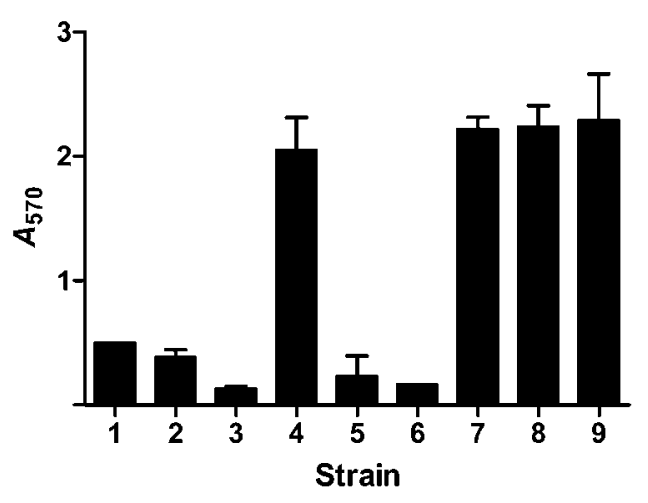

(c)

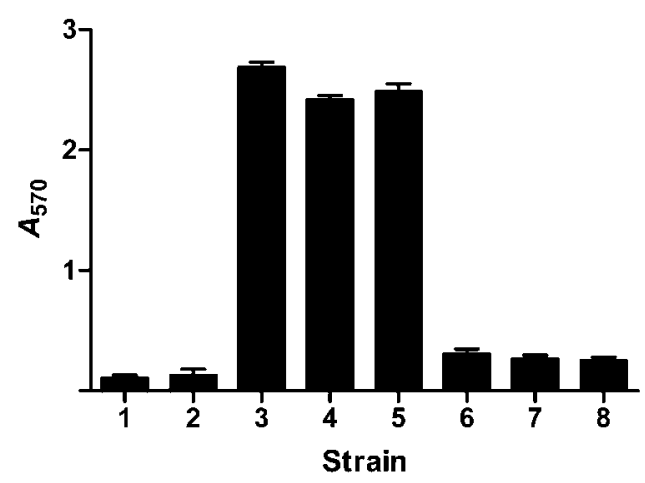

(b)

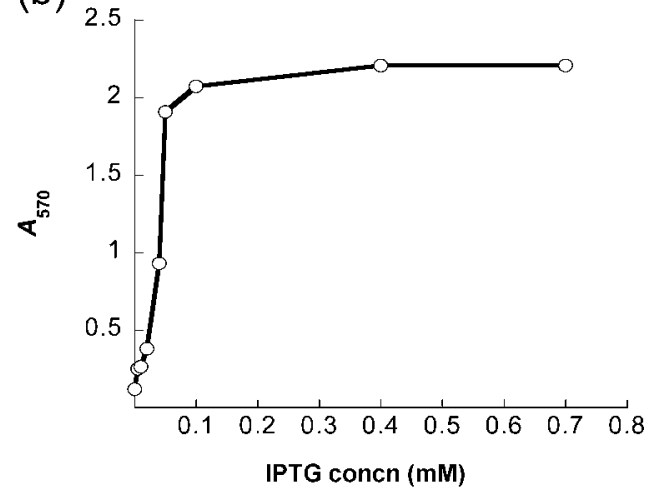

(d)

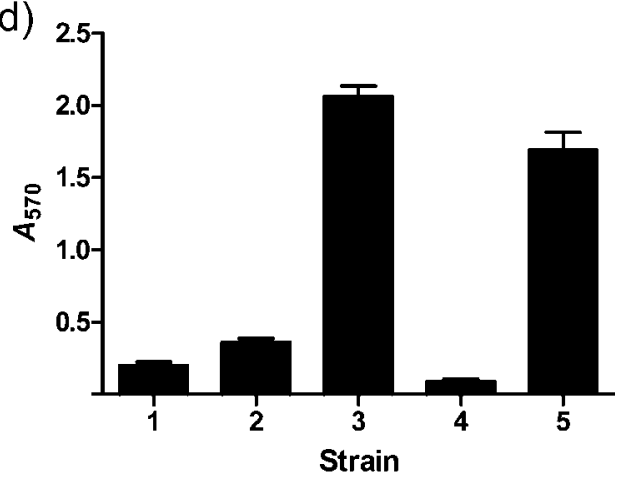

Fig. 8. Biofilm formation by SasG-expressing strains. (a) Biofilm formation by 1, S. aureus SH1000; 2, SH1000 with IPTG; 3 , SH1000 sasG:: pMUTIN4; 4, SH1000 sasG::pMUTIN4 with IPTG; 5, SH1000 (pALC2073); 6, SH1000 (pALC2073) with tetracycline; 7, SH1000 (pALC2073sas $\left.{ }^{+}\right) ; 8, \quad \mathrm{SH} 1000 \quad\left(\mathrm{pALC} 2073\right.$ sas $\mathrm{G}^{+}$) with tetracycline; 9, SH1000 ica (pALC2073sas ${ }^{+}$). (b) Biofilm formation by strain SH1000 sasG : : pMUTIN4. The biofilm formation was measured with inducer concentrations ranging from 0 to $0.7 \mathrm{mM}$. (c) Effect of differing $B$ repeat length variants on biofilm formation: 1, SH1000; , SH1000 (pALC2073); 3, SH1000 (pALC2073sasG ${ }^{+}$); 4, SH1000 (pALC2073sasG ${ }^{+}$6R); 5, SH1000 (pALC2073sasG ${ }^{+}$ 5R); 6, SH1000 (pALC2073*sasG ${ }^{+}$4R); 7, SH1000 (pALC2073*sasG ${ }^{+}$2R); 8, SH1000 (pALC2073*sasG ${ }^{+} 1 \mathrm{R}$ ). (d) Effect of the protease inhibitor $\alpha_{2}$-macroglobulin on SasG-mediated biofilm formation: 1, SH1000; 2, SH1000 (pALC2073); 3, SH1000 $\left(\mathrm{pALC2073sasG}{ }^{+}\right)$; 4, SH1000 (pALC2073sasG ${ }^{+}$) with $\alpha_{2}$-macroglobulin; 5, SH1000 (pALC2073sasG ${ }^{+}$) with heatinactivated $\alpha_{2}$-macroglobulin. Biofilm was measured using crystal violet staining and read at $A_{570}$. All experiments were done in triplicate; error bars show SDs.

dissemination throughout the body via the bloodstream. Furthermore, if adherence to squames is biologically important, then masking of the ClfB adhesin is not an issue, because SasG itself promotes strong adhesion to these cells. Also, formation of biofilm might be involved in colonization of the nasal epithelium by promoting stronger adhesion to the squamous epithelium and allowing bacterial cells to adhere to each other.

As with masking, biofilm formation was clearly shown to be dependent on the level of expression of the protein and the number of $\mathrm{B}$ repeats. It was also shown to be independent of the ica-encoded polysaccharide PIA. The related protein Aap from S. epidermidis can also promote biofilm formation independently of ica (Rohde et al., 2005). In this case, proteolytic cleavage of the A domain is a necessary precursor for cell-cell interactions by the exposed B domains (Rohde et al., 2005). Biofilm formation

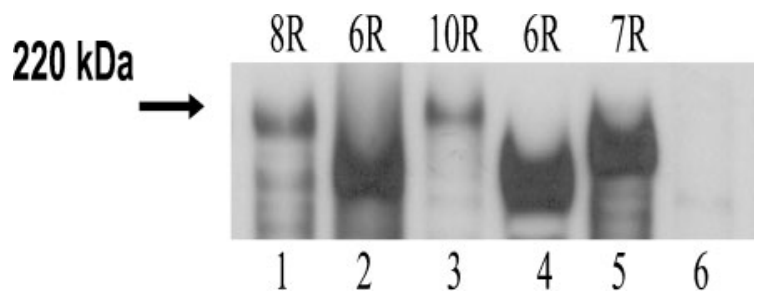

Fig. 9. Western immunoblot showing expression of SasG from clinical isolates of $S$. aureus. Lanes: $1,8325-4$ sasG: : pMUTIN4 induced with 0.4 mM IPTG; 2, strain 207; 3, strain 410; 4, strain $3093 ; 5$, strain $125 ; 6$, strain 315 . Cell wall proteins were released by lysostaphin digestion, run on $7.5 \%$ SDS-PAGE gels and probed with anti-SasG A domain antibodies. The different numbers of $B$ repeats $(R)$ present in each gene are indicated. The positions of standard molecular mass proteins (in $\mathrm{kDa}$ ) are marked. 
by SasG is also likely to be protease dependent, because the broad-spectrum protease inhibitor $\alpha_{2}$-macroglobulin inhibited the process. One could then hypothesize that the A domain of Sas $G$ must be proteolytically cleaved, enabling $\mathrm{B}-\mathrm{B}$ interactions between proteins on neighbouring cells. This would explain why the repeat length of SasG is important, as the protein would need to be long enough to reach another cell. It is also feasible that a mixed biofilm is promoted by interaction between SasG and Aap if the proteins can interact heterologously. An alternative mechanism of biofilm formation mentioned by Rohde $e t$ al. (2005) involves the interaction of the B domain with a ligand on the staphylococcal cell surface, in which case the repeats would also need to be of sufficient length to adhere to adjacent cells. The mechanism of biofilm formation promoted by SasG is currently under investigation.

\section{ACKNOWLEDGEMENTS}

T. J. F. would like to acknowledge the support of Science Foundation Ireland (grant no. 03/IN3/B370).

\section{REFERENCES}

Banner, M. A., Cunniffe, J. G., Macintosh, R. L., Foster, T. J., Rohde, H., Mack, D., Hoyes, E., Derrick, J., Upton, M. \& Handley, P. S. (2007). Localized tufts of fibrils on Staphylococcus epidermidis NCTC 11047 are comprised of the accumulation associated protein. J Bacteriol 189, 2793-2804.

Bateman, B. T., Donegan, N. P., Jarry, T. M., Palma, M. \& Cheung, A. L. (2001). Evaluation of a tetracycline-inducible promoter in Staphylococcus aureus in vitro and in vivo and its application in demonstrating the role of $\operatorname{sig} B$ in microcolony formation. Infect Immun 69, 7851-7857.

Chuard, C., Lucet, J. C., Rohner, P., Herrmann, M., Auckenthaler, R., Waldvogel, F. A. \& Lew, D. P. (1991). Resistance of Staphylococcus aureus recovered from infected foreign body in vivo to killing by antimicrobials. J Infect Dis 163, 1369-1373.

Clarke, S. R., Brummell, K. J., Horsburgh, M. J., McDowell, P. W., Mohamad, S. A., Stapleton, M. R., Acevedo, J., Read, R. C., Day, N. P. \& other authors (2006). Identification of in vivo-expressed antigens of Staphylococcus aureus and their use in vaccinations for protection against nasal carriage. J Infect Dis 193, 1098-1108.

Day, N. P., Moore, C. E., Enright, M. C., Berendt, A. R., Smith, J. M., Murphy, M. F., Peacock, S. J., Spratt, B. G. \& Feil, E. J. (2001). A link between virulence and ecological abundance in natural populations of Staphylococcus aureus. Science 292, 114-116.

Elliott, D., Harrison, E., Handley, P. S., Ford, S. K., Jaffray, E., Mordan, N. \& McNab, R. (2003). Prevalence of Csh-like fibrillar surface proteins among mitis group oral streptococci. Oral Microbiol Immunol $\mathbf{1 8}$ $114-120$

Fitzgerald, J. R., Loughman, A., Keane, F., Brennan, M., Knobel, M., Higgins, J., Visai, L., Speziale, P., Cox, D. \& Foster, T. J. (2006). Fibronectin-binding proteins of Staphylococcus aureus mediate activation of human platelets via fibrinogen and fibronectin bridges to integrin GPIIb/IIIa and IgG binding to the FcgammaRIIa receptor. Mol Microbiol 59, 212-230.

Fitzpatrick, F., Humphreys, H. \& O'Gara, J. P. (2005). Evidence for ica $A D B C$-independent biofilm development mechanism in methicillin-resistant Staphylococcus aureus clinical isolates. J Clin Microbiol 43, 1973-1976.

Foster, T. J. (1998). Molecular genetic analysis of staphylococcal virulence. In Methods in Microbiology, vol. 27, pp. 433-454. Edited by P. H. Williams, J. Ketley \& G. Salmond. Oxford, UK: Elsevier.

Foster, T. J. \& Hook, M. (1998). Surface protein adhesins of Staphylococcus aureus. Trends Microbiol 6, 484-488.

Handley, P. S., Carter, P. L., Wyatt, J. E. \& Hesketh, L. M. (1985). Surface structures (peritrichous fibrils and tufts of fibrils) found on Streptococcus sanguis strains may be related to their ability to coaggregate with other oral genera. Infect Immun 47, 217-227.

Heilmann, C., Schweitzer, O., Gerke, C., Vanittanakom, N., Mack, D. \& Gotz, F. (1996). Molecular basis of intercellular adhesion in the biofilm-forming Staphylococcus epidermidis. Mol Microbiol 20, 1083-1091.

Heilmann, C., Hussain, M., Peters, G. \& Gotz, F. (1997). Evidence for autolysin-mediated primary attachment of Staphylococcus epidermidis to a polystyrene surface. Mol Microbiol 24, 1013-1024.

Horsburgh, M. J., Aish, J. L., White, I. J., Shaw, L., Lithgow, J. K. \& Foster, S. J. (2002). $\sigma^{\mathrm{B}}$ modulates virulence determinant expression and stress resistance: characterization of a functional $r s b U$ strain derived from Staphylococcus aureus 8325-4. J Bacteriol 184, 5457-5467.

Kluytmans, J., van Belkum, A. \& Verbrugh, H. (1997). Nasal carriage of Staphylococcus aureus: epidemiology, underlying mechanisms, and associated risks. Clin Microbiol Rev 10, 505-520.

Kreiswirth, B. N., Lofdahl, S., Betley, M. J., O'Reilly, M., Schlievert, P. M., Bergdoll, M. S. \& Novick, R. P. (1983). The toxic shock syndrome exotoxin structural gene is not detectably transmitted by a prophage. Nature 305, 709-712.

Lindsay, J. A., Moore, C. E., Day, N. P., Peacock, S. J., Witney, A. A., Stabler, R. A., Husain, S. E., Butcher, P. D. \& Hinds, J. (2006). Microarrays reveal that each of the ten dominant lineages of Staphylococcus aureus has a unique combination of surface-associated and regulatory genes. J Bacteriol 188, 669-676.

Mack, D. (1999). Molecular mechanisms of Staphylococcus epidermidis biofilm formation. J Hosp Infect 43 (Suppl), S113-S125.

Mack, D., Becker, P., Chatterjee, I., Dobinsky, S., Knobloch, J. K., Peters, G., Rohde, H. \& Herrmann, M. (2004). Mechanisms of biofilm formation in Staphylococcus epidermidis and Staphylococcus aureus: functional molecules, regulatory circuits, and adaptive responses. Int $J$ Med Microbiol 294, 203-212.

Mazmanian, S. K., Ton-That, H. \& Schneewind, O. (2001). Sortasecatalysed anchoring of surface proteins to the cell wall of Staphylococcus aureus. Mol Microbiol 40, 1049-1057.

McAleese, F. M., Walsh, E. J., Sieprawska, M., Potempa, J. \& Foster, T. J. (2001). Loss of clumping factor B fibrinogen binding activity by Staphylococcus aureus involves cessation of transcription, shedding and cleavage by metalloprotease. J Biol Chem 276, 29969-29978.

McNab, R., Forbes, H., Handley, P. S., Loach, D. M., Tannock, G. W. \& Jenkinson, H. F. (1999). Cell wall-anchored CshA polypeptide (259 kilodaltons) in Streptococcus gordonii forms surface fibrils that confer hydrophobic and adhesive properties. J Bacteriol 181, 3087-3095.

Navarre, W. W. \& Schneewind, O. (1999). Surface proteins of Grampositive bacteria and mechanisms of their targeting to the cell wall envelope. Microbiol Mol Biol Rev 63, 174-229.

Ni Eidhin, D., Perkins, S., Francois, P., Vaudaux, P., Hook, M. \& Foster, T. J. (1998). Clumping factor B (ClfB), a new surface-located fibrinogen-binding adhesin of Staphylococcus aureus. Mol Microbiol 30, 245-257.

Novick, R. (1967). Properties of a cryptic high-frequency transducing phage in Staphylococcus aureus. Virology 33, 155-166. 
O’Brien, L. M., Walsh, E. J., Massey, R. C., Peacock, S. J. \& Foster, T. J. (2002). Staphylococcus aureus clumping factor B (ClfB) promotes adherence to human type I cytokeratin 10: implications for nasal colonization. Cell Microbiol 4, 759-770.

Peacock, S. J., de Silva, I. \& Lowy, F. D. (2001). What determines nasal carriage of Staphylococcus aureus? Trends Microbiol 9, 605-610.

Roche, F. M., Massey, R., Peacock, S. J., Day, N. P., Visai, L., Speziale, P., Lam, A., Pallen, M. \& Foster, T. J. (2003a). Characterization of novel LPXTG-containing proteins of Staphylococcus aureus identified from genome sequences. Microbiology 149, 643-654.

Roche, F. M., Meehan, M. \& Foster, T. J. (2003b). The Staphylococcus aureus surface protein SasG and its homologues promote bacterial adherence to human desquamated nasal epithelial cells. Microbiology 149, 2759-2767.

Rohde, H., Burdelski, C., Bartscht, K., Hussain, M., Buck, F., Horstkotte, M. A., Knobloch, J. K., Heilmann, C., Herrmann, M. \& Mack, D. (2005). Induction of Staphylococcus epidermidis biofilm formation via proteolytic processing of the accumulation-associated protein by staphylococcal and host proteases. Mol Microbiol 55, 1883-1895.

Sambrook, J. \& Russell, D. W. (2001). Molecular Cloning: a Laboratory Manual, 3rd edn. Cold Spring Harbor, NY: Cold Spring Harbor Laboratory.

Saravia-Otten, P., Muller, H. P. \& Arvidson, S. (1997). Transcription of Staphylococcus aureus fibronectin binding protein genes is negatively regulated by $a g r$ and an $a g r$-independent mechanism. $J$ Bacteriol 179, 5259-5263.

Savolainen, K., Paulin, L., Westerlund-Wikstrom, B., Foster, T. J., Korhonen, T. K. \& Kuusela, P. (2001). Expression of pls, a gene closely associated with the mecA gene of methicillin-resistant Staphylococcus aureus, prevents bacterial adhesion in vitro. Infect Immun 69, 3013-3020.

Schaffer, A. C., Solinga, R. M., Cocchiaro, J., Portoles, M., Kiser, K. B., Risley, A., Randall, S. M., Valtulina, V. \& Speziale, P. (2006). Immunization with Staphylococcus aureus clumping factor B, a major determinant in nasal carriage, reduces nasal colonization in a murine model. Infect Immun 74, 2145-2153.

Telford, J. L., Barocchi, M. A., Margarit, I., Rappuoli, R. \& Grandi, G. (2006). Pili in Gram-positive pathogens. Nat Rev Microbiol 4, 509-519.

Toledo-Arana, A., Merino, N., Vergara-Irigaray, M., Debarbouille, M., Penades, J. R. \& Lasa, I. (2005). Staphylococcus aureus develops an alternative, ica-independent biofilm in the absence of the arlRS twocomponent system. J Bacteriol 187, 5318-5329.

Vagner, V., Dervyn, E. \& Ehrlich, S. D. (1998). A vector for systematic gene inactivation in Bacillus subtilis. Microbiology 144, 3097-3104.

Weerkamp, A. H., Handley, P. S., Baars, A. \& Slot, J. W. (1986). Negative staining and immunoelectron microscopy of adhesiondeficient mutants of Streptococcus salivarius reveal that the adhesive protein antigens are separate classes of cell surface fibril. J Bacteriol 165, 746-755.

Zhang, L., Fan, F., Palmer, L. M., Lonetto, M. A., Petit, C., Voelker, L. L., St John, A., Bankosky, B., Rosenberg, M. \& McDevitt, D. (2000). Regulated gene expression in Staphylococcus aureus for identifying conditional lethal phenotypes and antibiotic mode of action. Gene 255, 297-305.

Edited by: T. Msadek 